\title{
Editorial
}

\section{Gemtuzumab Ozogamicin (Mylotarg) and hepatic veno-occlusive disease: take two acetaminophen, and ...}

\author{
LI Gordon
}

Department of Medicine, Division of Hematology/Oncology, Northwestern University Medical School and The Robert H Lurie Comprehensive Cancer Center of Northwestern University, Chicago, IL, USA

The earliest description of what later proved to be hepatic veno-occlusive disease appeared in 1911. ${ }^{1}$ These studies described hepatic injury in cattle following alkaloid ingestion. A similar pattern of liver injury was later recognized in humans as a non-portal cirrhosis, ${ }^{2}$ and the term hepatic veno-occlusive disease (HVOD) was first used. The characteristic centrilobular pattern was described and was different from the pattern of cirrhosis that was recognized in other forms of liver disease. Most of these early cases of HVOD occurred as a consequence of food poisoning from plant-derived alkaloids. ${ }^{3,4}$ In the late 1970s, as bone marrow transplantation for the treatment of aplastic anemia and malignancy become more common, HVOD was observed as a frequent complication ${ }^{5-9}$ and was often fatal. ${ }^{10,11}$ The mechanism of the liver injury was unclear, and the lack of an animal model hampered research in this area. It was uncertain whether hepatocytes were injured first or whether sinusoidal endothelial cells (SECs) were the major target. What seemed clear was that stem cell transplant regimens which contained alkylating agents ${ }^{12}$ or total body irradiation $^{13}$ given at high doses predicted development of HVOD, as did pre-existing liver disease. However, the variability in severity and time course (as early as 10 days, as late as several months after presumed insult) clouded an understanding of pathophysiology.

One constant in animal experiments seemed to be the reproducible injury induced by pyrrolizidine compounds such as monocrotaline. This alkaloid is activated by the liver p-450 oxidase system, and is conjugated to glutathione. ${ }^{14}$ These observations led to a series of elegant experiments by DeLeve et al, ${ }^{15}$ who described selective toxicity to the SEC rather than the hepatocyte, by a mechanism that was enhanced by depletion of and reversed by repletion of glutathione (GSH). As little as $100 \mu \mathrm{M} / 1$ exogenous GSH reduced monocrotaline and azathioprine (metabolized in the liver and intestine by GSH Stransferase) toxicity in SECs. An animal model of HVOD was established, in which monocrotaline-induced liver damage could be predicted. ${ }^{16}$ The characteristic pathologic

Correspondence: LI Gordon, Department of Medicine, Division of Hematology/Oncology, Northwestern University Medical School and The Robert H Lurie Comprehensive Cancer Center of Northwestern University, 676 N St Clair, Suite 850, Chicago, IL 60611, USA

Received and accepted 31 July 2001 lesion of early SEC damage followed by coagulative necrosis, hepatocyte damage and central vein fibrosis was described over a 10-day period in the animal system. This pattern was thought to be most similar to the human HVOD associated with alkaloid exposure or high-dose chemotherapy and stem cell transplantation, but not to radiationinduced liver disease. ${ }^{17,18}$

The consistent finding that GSH depletion predisposes to the liver injury raises the question of whether a common denominator in the pathophysiology of this process is free radical damage. GSH is a reducing agent, which protects the cell from toxic free radical and electrophilic compounds generated during cellular metabolism. We, ${ }^{19}$ and others ${ }^{20}$ have raised the question of whether a pro-oxidant state is created in the setting of stem cell transplantation by the increased saturation of transferrin and measurable free iron which may occur by a variety of possible mechanisms. We have speculated that the likely end result is a pro-oxidant state in which free radical damage to end organs may be enhanced. ${ }^{19}$ A confounding and potentially important component of enhanced free radical injury potentiated by chemotherapy is acetaminophen, the commonly used antipyretic and pain reliever. Acetaminophen is metabolized via glucuronidation (in the liver with the production of sulfate or glucuronic acid) pathways, and a small amount is oxidized by cytochrome p-450 2E1. Acetaminophen toxicity is seen when the dose exceeds $4 \mathrm{~g}$ in a $24-\mathrm{h}$ period, but prior alcohol use or liver disease increases the risk. The successful treatment of acetaminophen overdose with the sulfhydryl donor/free radical scavenger N-acetylcysteine $^{21,22}$ suggests that the mechanism of injury is indeed related to depletion of GSH and is free radical mediated.

The report by Tack and colleagues ${ }^{23}$ from Mayo Clinic in this issue of Bone Marrow Transplantation describing HVOD following Mylotarg (Wyeth, Philadelphia, PA, USA) (gemtuzumab ozogamicin) is intriguing, since this observation suggests a possible mechanism and potential for prevention. Mylotarg is an anti-CD33 antibody linked to calicheamicin, which is a free radical generating antitumor antibiotic. Although not addressed in this report, it is common practice to administer acetaminophen prior to Mylotarg, in order to ameliorate the fever and chills seen with the antibody. Indeed, in the original report by Sievers et $a l^{24}$ acetaminophen was routinely administered to all patients prior to Mylotarg and up to $4 \mathrm{~g}$ of acetaminophen 
is recommended by the manufacturer in the package insert. The resulting manipulation of the glutathione redox system leaves the SECs naked and exposed to the potential free radical attack (calicheamicin) targeted to CD33 antigen. ${ }^{25,26}$ This localized pro-oxidant state may leave the SEC and then the hepatocyte vulnerable to free radical injury and HVOD.

This report by Tack et $a l^{23}$ coupled with animal studies on the pathophysiology of HVOD ${ }^{15,16,27}$ suggests that until the mechanism of HVOD associated with Mylotarg is more clearly elucidated, acetaminophen should be avoided in this setting. Further, more detailed clinical studies investigating the mechanism of HVOD should be carried out, including investigations focusing specifically on markers of free radical injury to DNA (the DNA adduct 8-hydroxydeoxyguanosine), the cell membrane (lipid peroxidation products), and the impact of a pro-oxidant state on treatment-related toxicity.

\section{References}

1 Cushny AR. On the action of senecio alkaloids and the causation of the hepatic cirrhosis of cattle. J Pharmacol Exp Ther 1911; 2: 531-548.

2 Bras G, Jeliffe DB, Stuart KL. Veno-occlusive disease of the liver with non-portal type of cirrhosis occurring in Jamaica. Arch Pathol 1954; 57: 285-300.

3 Steenkamp V, Stewart MJ, Zuckerman M. Clinical and analytical aspects of pyrrolizidine poisoning caused by South African traditional medicines. Ther Drug Monitoring 2000; 22: 302-306.

4 Prakash AS, Pereira TN, Reilly PE et al. Pyrrolizidine alkaloids in human diet. Mutat Res 1999; 443: 53-67.

5 Berk PD, Popper H, Krueger GR et al. Veno-occlusive disease of the liver after allogeneic bone marrow transplantation: possible association with graft-versus-host disease. Ann Intern Med 1979; 90: 158-164.

6 Shulman HM, McDonald GB, Mathews D. An analysis of hepatic veno-occlusive disease and centrilobular hepatic degeneration following bone marrow transplantation. Gastroenterology 1980; 79: 1178-1191.

7 Bearman SI. Veno-occlusive disease of the liver. Curr Opin Oncol 2000; 12: 103-109.

8 Carreras E. Veno-occlusive disease of the liver after hemopoietic cell transplantation. Eur J Haematol 2000; 64: 281-291.

9 Richardson P, Guinan E. The pathology, diagnosis, and treatment of hepatic veno-occlusive disease: current status and novel approaches. Br J Haematol 1999; 107: 485-493.

10 Hasegawa S, Horibe K, Kawabe T et al. Veno-occlusive disease of the liver after allogeneic bone marrow transplantation in children with hematologic malignancies: incidence, onset time and risk factors. Bone Marrow Transplant 1998; 22: 1191-1197.

11 Lee JL, Gooley T, Bensinger W et al. Veno-occlusive disease of the liver after busulfan, melphalan, and thiotepa condition- ing therapy: incidence, risk factors, and outcome. Biol Blood Marrow Transplant 1999; 5: 306-315.

12 Cavo M, Bandini G, Benni M et al. High-dose busulfan and cyclophosphamide are an effective conditioning regimen for allogeneic bone marrow transplantation in chemosensitive multiple myeloma. Bone Marrow Transplant 1998; 22: 27-32.

13 Ozsahin M. Does total-body irradiation technique influence veno-occlusive disease incidence? J Clin Oncol 2000; 18: 3062-3063.

14 Yan CC, Huxtable RJ. Relationship between glutathione concentration and metabolism of the pyrrolizidine alkaloid, monocrotoline, in the isolated perfused liver. Toxicol Appl Pharmacol 1995; 130: 132-139.

15 DeLeve LD, Wang X, Kuhlenkamp JF et al. Toxicity of azathioprine and monocrotaline in murine sinusoidal endothelial cells and hepatocytes: the role of glutathione and relevance to hepatic venoocclusive disease. Hepatology 1996; 23: 589599.

16 DeLeve LD, McCuskey RS, Wang X et al. Characterization of a reproducible rat model of hepatic veno-occlusive disease. Hepatology 1999; 29: 1779-1791.

17 Reed GB, Cox AJ. The human liver after radiation injury: a form of veno-occlusive disease. Am J Pathol 1966; 48: 597-611.

18 Fajardo LF, Colby TV. Pathogenesis of veno-occlusive liver disease after radiation. Arch Pathol Lab Med 1980; 104: 584-588.

19 Gordon LI, Brown SG, Tallman MS et al. Sequential changes in serum iron and ferritin in patients undergoing high-dose chemotherapy and radiation with autologous bone marrow transplantation: possible implications for treatment related toxicity. Free Rad Biol Med 1995; 18: 383-389.

20 Durken M, Agbenu J, Finckh B et al. Deteriorating free radical-trapping capacity and antioxidant status during bone marrow transplantation. Bone Marrow Transplant 1995; 15: 757-762.

21 Smilkstein MJ, Knapp GL, Kulig KW et al. Efficacy of oral $\mathrm{N}$-Acetylcysteine in the treatment of acetominophen overdose: analysis of the national multi-center study (1976 to 1985). New Engl J Med 1988; 319: 1557-1562.

22 Harrison PM, Keays R, Bray GP et al. Improved outcome of paracetamol-induced fulminant hepatic failure by late administration of acetylcysteine. Lancet 1990; 335: 1572-1573.

23 Tack DK, Letendre L, Kanath PS, Tefferi A. Development of hepatic veno-occlusive disease after Mylotarg infusion for relapsed acute myeloid leukemia. Bone Marrow Transplant 2001; 28: 895-897.

24 Sievers EL, Appelbaum FR, Speilberger RT et al. Selective ablation of acute myeloid leukemia using antibody-targeted chemotherapy: a phase I study of an anti-CD33 calicheamicin immunoconjugate. Blood 1999; 93: 3678-3684.

25 Sato Y, Asada Y, Hara S et al. Hepatic stellate cells (Ito cells) in veno-occlusive disease of the liver after allogeneic bone marrow transplantation. Histopathology 1999; 34: 66-70.

26 Muench MO, Cupp J, Polakoff J et al. Expression of CD33, CD38, and HLA-DR on CD34+ human fetal liver progenitors with a high proliferative potential. Blood 1994; 83: 31703181.

27 DeLeve LD. Glutathione defense in non-parenchymal cells. Semin Liver Dis 1998; 18: 403-413. 